\title{
DYNAMIC FRACTURE OF L AND CT CONCRETE SPECIMENS: NUMERICAL AND EXPERIMENTAL STUDIES
}

\author{
J. OŽBOLT ${ }^{*}$, A. SHARMA ${ }^{\dagger}$ AND N. BEDE ${ }^{\dagger \dagger}$ \\ *University of Stuttgart \\ Stuttgart, Germany \\ e-mail: ozbolt@iwb.uni-stuttgart.de \\ ${ }^{\dagger}$ University of Stuttgart \\ Stuttgart, Germany \\ e-mail: akanshu.sharma@iwb.uni-stuttgart.de \\ ${ }^{\dagger}$ University of Rijeka \\ Rijeka, Croatia \\ e-mail: natalija.bede@gradri.uniri.hr
}

Key words: Dynamic fracture, L and CT Specimen, Experiments, Finite Element Analysis

\begin{abstract}
To confirm the findings of recent numerical studies and to obtain the experimental evidence on dynamic fracture of concrete, experimental tests were performed on L- and CTspecimens. The experiments fully confirmed the results of previously performed numerical studies. It is shown that inertia effects are responsible for progressive increase of resistance, crack branching and rate dependent crack propagation. The presented, relatively simple, tests can be used to check whether numerical model is able to realistically predict complex phenomena related to dynamic fracture of concrete.
\end{abstract}

\section{INTRODUCTION}

The resistance, failure mode, crack pattern and crack velocity in concrete are strongly influenced by loading rate [1-8]. The rate dependent response of concrete is controlled through three different effects: (i) through the rate dependency of the growing microcracks (influence of inertia at the micro level), (ii) through the viscous behavior of the bulk material between the cracks (viscosity due to the water content) and (iii) through the influence of inertia, which comes from different sources [9]. Performing analysis on macro or meso-scale, the first two effects can be accounted for by the constitutive law and the third effect, assuming that the resolution of finite elements is fine enough, should be automatically accounted for through dynamic analysis, where the constitutive law interacts with structural inertia [9-12]. For quasi-brittle materials, such as concrete, the first two effects are important for relatively low and medium strain rates. For higher strain rates (impact) the influence of inertia dominates, however, the rate dependency cannot be neglected [13].

There are different aspects of inertia, which need to be considered namely, (i) structural inertia, which is present even in case of elastic analysis, (ii) inertia activated due to the material softening or hardening (e.g. lateral compressive forces in uniaxial compression tests) or (iii) inertia at the crack tip that is responsible for crack branching. Principally, 
with the increase of loading rate, the failure mode tends to change from mode-I to mixed mode. As discussed by Ožbolt et al. [9-12] this is attributable to the structural inertia, which homogenizes the material in the impact zone and forces the crack to move away from the zone of high inertia effect. Moreover, with the change of the failure mode, structural resistance also changes.

From the experimental and numerical evidence is known that the crack propagation velocity depends on loading rate. The maximum crack velocity, theoretically achievable, is the Rayleigh wave speed $v_{\mathrm{R}}=C_{\mathrm{R}}\left(G_{\mathrm{c}} / \rho_{\mathrm{c}}\right) 0.5$ where the constant $C_{\mathrm{R}}$ depends on Poisson's ratio, $G_{\mathrm{c}}$ is the shear modulus and $\rho_{\mathrm{c}}$ is specific weight of the material. For normal strength concrete, the Rayleigh wave speed is approximately equal to $2100 \mathrm{~m} / \mathrm{s}$. However, experimental [4], theoretical [1,2] and numerical investigations [9-12] indicate that a single mode-I type of crack cannot reach this theoretical velocity. According to these investigations the maximum achievable crack speed, in normal strength concrete is between 500 and $800 \mathrm{~m} / \mathrm{s}$.

L-shape and compact tension (CT) specimens are frequently used to verify prediction of numerical models for concrete. However, experimental and numerical fracture studies exist mainly for quasi-static loading. In relatively recent numerical studies $[9,12]$ the influence of loading rate on fracture of $\mathrm{L}$ - and CT-specimen made of normal strength concrete was investigated. The main conclusions of the studies can be summarized as follows: (i) with the increase of loading rate the resistance increases approximately linear (in semi-log scale) up to the critical loading rate. For this range of loading rate, the rate dependent constitutive law controls the resistance. However, for higher loading rates there $\mathrm{a}$ is progressive increase of resistance, which is controlled mainly by inertia effects and not by the rate dependent strength of concrete; (ii) Crack pattern and propagation are rate dependent. It was concluded that inertia effects are responsible for the change of crack direction.

To experimentally confirm the numerical results, tests on the same specimens were carried out. Due to technical reasons, the geometry and loading of the L- and CTspecimens were not exactly the same as in the previously performed numerical studies. Therefore, the post-test numerical analysis of tested specimens was also carried out using the same finite element code as reported in $[9,10]$.

In the present contribution the summary of experimental and numerical results are presented and discussed. It is important to note that these, relative simple, experimental tests can be useful for verification and calibration of numerical models for concrete.

\section{EXPERIMENTAL STUDIES}

As mentioned above, to verify numerical results recently published in $[9,10]$, experimental tests on concrete L- and CTspecimens were carried out for relatively high loading rates. The experiments were performed at Material Testing Institute (MPA), University of Stuttgart.

\subsection{L-Specimen}

The dimensions of the tested L-specimen (Width $\times$ Height $\times$ Thickness) are: $\mathrm{W} \times \mathrm{H} \times \mathrm{T}=$ $500 \times 500 \times 50 \mathrm{~mm}$. The specimen geometry and the test set-up are shown in Fig. 1. The specimen was fixed on the two sides with steel plates, which are rigidly bolted to the supporting plate. The load is applied at the bottom free side of the specimen in upward direction close to the edge. The centroid of the loading force is $30 \mathrm{~mm}$ from the free specimen edge.

The specimens were loaded in displacement control. An INSTRON servo-hydraulic high speed testing machine is used to apply different displacement rates to the machine actuator (loading piston) in the direction opposite to gravity. The imposed loading point displacement rates were varied from 0.25 $\mathrm{mm} / \mathrm{s}$ up to $5.0 \mathrm{~m} / \mathrm{s}$. Due to safety reasons the tests were not performed for higher loading (displacement) rates.

The concrete specimens were cured for 7 days under constant temperature of $20^{\circ} \mathrm{C}$ and relative humidity $(\mathrm{RH})$ of $100 \%$. Subsequently 
they were exposed to $\mathrm{RH}$ of $60 \%$. The age of the concrete at testing was approximately 4 months. The uniaxial compressive strength and the splitting tensile strength were measured using the standard cubes with dimensions of $150 \times 150 \times 150 \mathrm{~mm}$, following the procedures recommended by DIN-EN-12490. Two concrete mixes were tested. For each concrete mix, $10 \mathrm{~L}$-specimens were cast. The average material properties obtained for each concrete mixture are summarized in Tab. 1 .

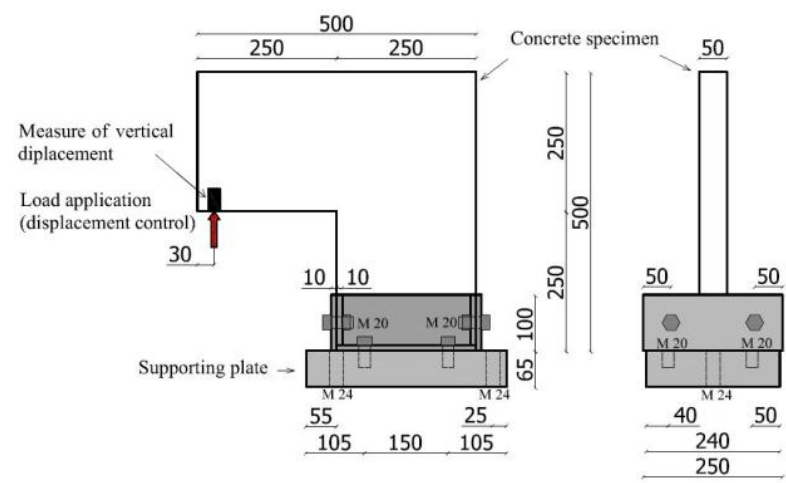

Figure 1: Geometry and test set-up of L-specimen.

Table 1: Summary of concrete properties

\begin{tabular}{cccc}
\hline Batch & $\begin{array}{c}\text { Density } \\
\rho_{\mathrm{c}} \\
\left(\mathrm{kg} / \mathrm{m}^{3}\right)\end{array}$ & $\begin{array}{c}\text { Tensile splitting } \\
\text { strength } \\
f_{t, \mathrm{sp}}(\mathrm{MPa})\end{array}$ & $\begin{array}{c}\text { Compressive } \\
\text { strength } \\
f_{\mathrm{cc}}(\mathrm{MPa})\end{array}$ \\
\hline \hline 1 & 2205 & 3.5 & 51.4 \\
2 & 2214 & 3.5 & 56.4 \\
\hline
\end{tabular}

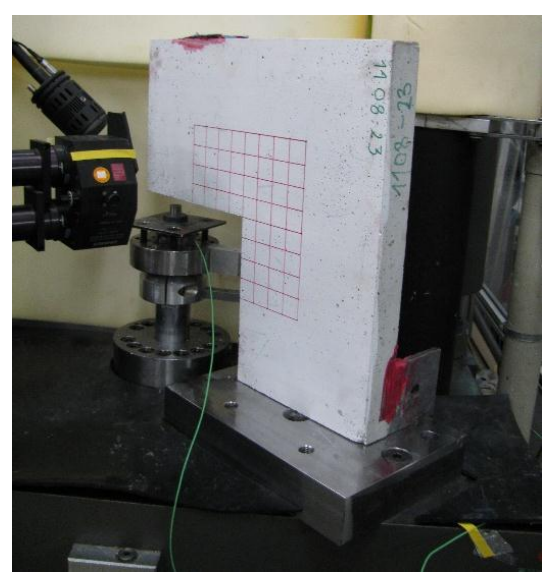

Figure 2: Test set-up.

The test set-up and the measuring equipment are shown in Fig. 2. The load cell built into the inner part of the loading piston (machine actuator) was used to measure the applied load. KISTLER piezoelectric force sensor Type 9061A was employed to determine the dynamic forces. The vertical displacement was monitored just above the point of load application, $30 \mathrm{~mm}$ away from the left vertical edge on the front surface of tested specimen. FASTCAM-APX RS highspeed video camera (HSC) with a maximum of 30000 frames per second was employed to record the crack propagation. From the record of crack propagation, crack velocity was evaluated.

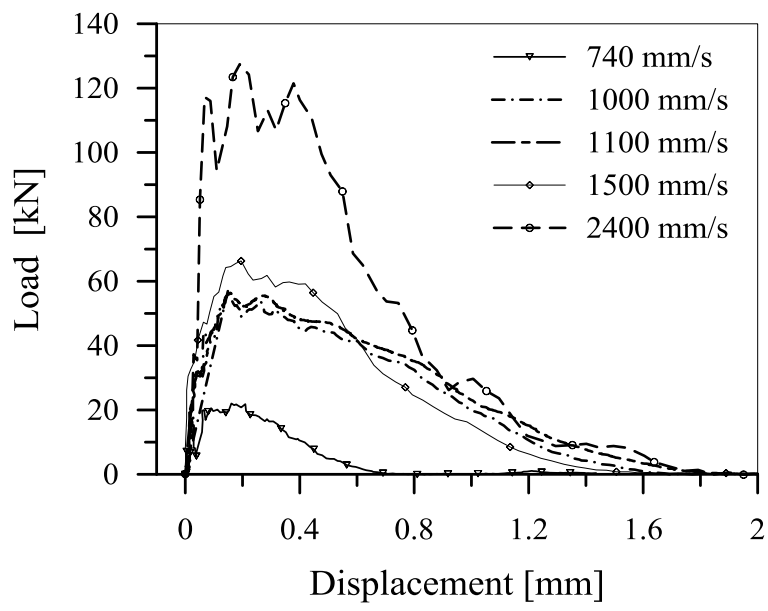

Figure 3: Experimentally measured load-displacement response for loading rates larger than $0.740 \mathrm{~m} / \mathrm{s}$.

Table 2: Experimental results for L-specimen

\begin{tabular}{cccc}
\hline \multicolumn{3}{c}{ Displacement rate $(\mathrm{m} / \mathrm{s})$} & \\
\cline { 1 - 3 } Test & Machine & Specimen & Peak load $(\mathrm{kN})$ \\
\hline \hline 1 & 0.00025 & 0.00025 & 4.00 \\
2 & 0.10 & 0.082 & 4.88 \\
3 & 0.50 & 0.35 & 13.96 \\
4 & 1.00 & 0.74 & 22.30 \\
5 & 2.00 & 1.20 & 48.54 \\
6 & 2.50 & 1.30 & 56.16 \\
7 & 2.50 & 1.15 & 51.95 \\
8 & 3.00 & 1.00 & 56.93 \\
9 & 4.00 & 1.10 & 56.35 \\
10 & 1.00 & 0.71 & 35.74 \\
11 & 3.00 & 1.50 & 66.41 \\
12 & 4.50 & 2.40 & 127.73 \\
\hline
\end{tabular}

In total 12 experimental results obtained from performed tests are evaluated. The machine actuator displacement rates, the actual 
displacement rates measured on the tested specimens and the corresponding peak loads are summarized in Tab. 2. The actual displacement rates are given as maximum displacement rates defined by a tangent on the displacement history output curve that corresponds to the peak load, i.e. just before onset of cracking.

The measured load-displacement curves for typical tests are plotted in Fig. 3. It is clear that the peak load increases with increasing displacement rate. The highest load of approximately $130 \mathrm{kN}$ is obtained in the test No. 12, which corresponds to the highest loading rate of approximately $2.40 \mathrm{~m} / \mathrm{s}$. In Fig. 4, the peak load obtained for each test is plotted as a function of the corresponding displacement rate in semi-logarithmic scale. It can be observed that for loading rates larger than approximately $0.10 \mathrm{~m} / \mathrm{s}$ peak the load starts to increase progressively.

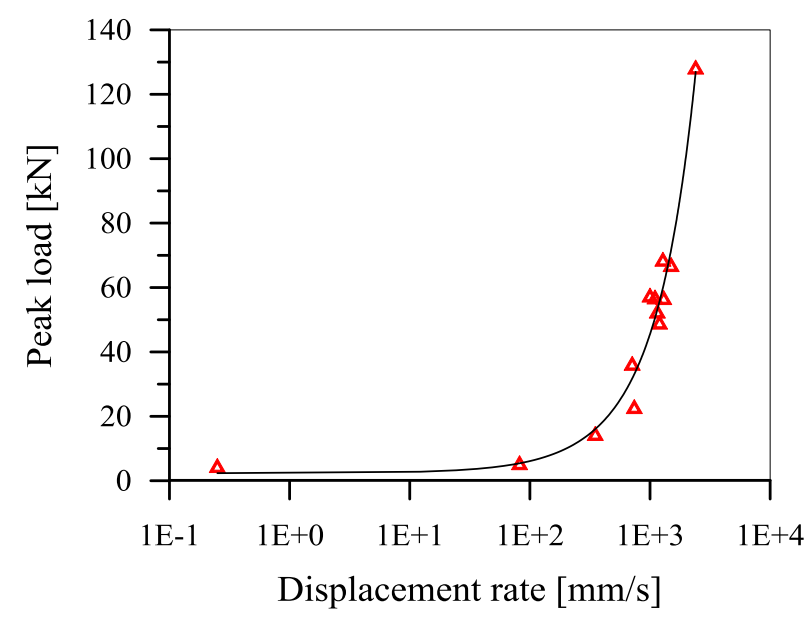

Figure 4: Peak load measured for different displacement rates.

In Fig. 5, typical crack patterns obtained from the tests performed at different displacement rates are shown. It can be clearly seen that there is a significant difference in the failure patterns between relatively low and higher loading rates. The failure patterns correspond very well with the predictions obtained in [10] and the crack propagation changes direction with the increase of loading rate. It is interesting to note that the crack always initiates from the same point (inner corner of the specimen) and propagates into the specimen, however, the direction of crack propagation is different. For relatively low displacement rates, close to quasi-static, the crack propagates in horizontal direction, almost perpendicular to the loading direction (see Fig. 5a). With increasing loading rate, the direction of crack initiation and propagation tends to rotate towards vertical, almost parallel to the loading direction (see Fig. 5c,d). Furthermore, in most cases with higher displacement rates there is crack branching and a number of smaller cracks with crack bridging (Fig. 6). (a)

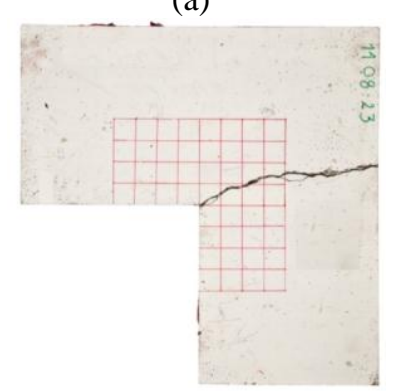

(c)

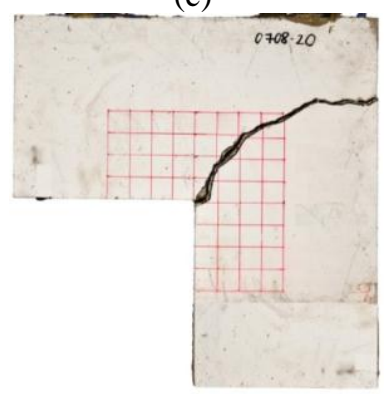

(e)

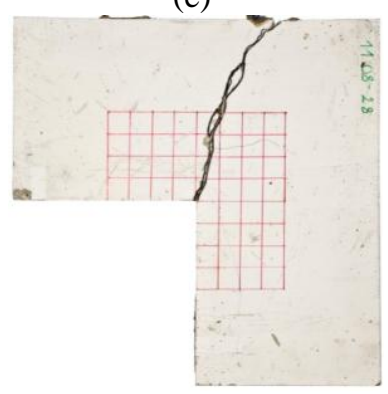

(b)

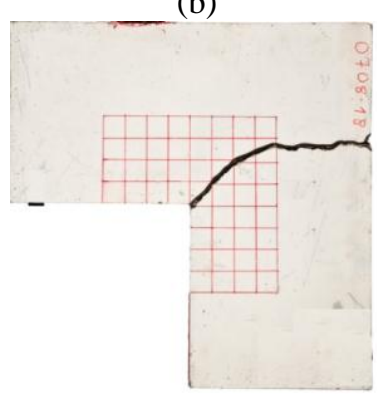

(d)

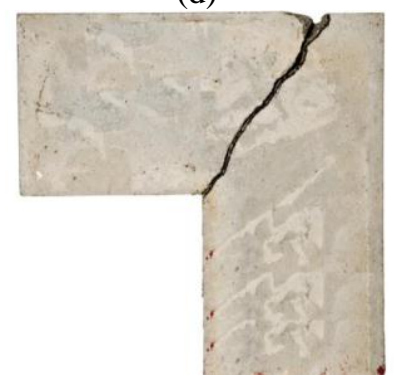

(f)

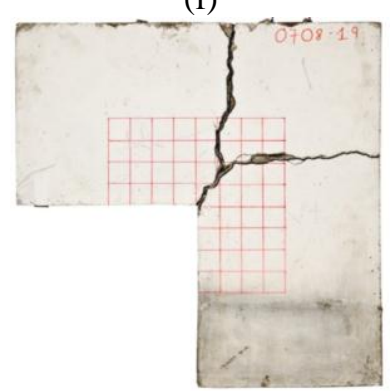

Figure 5: Typical crack patterns for loading rates: (a) 0.25, (b) 350, (c) 710, (d) 740, (e) 1100 and (f) 2400 $\mathrm{mm} / \mathrm{s}$. 


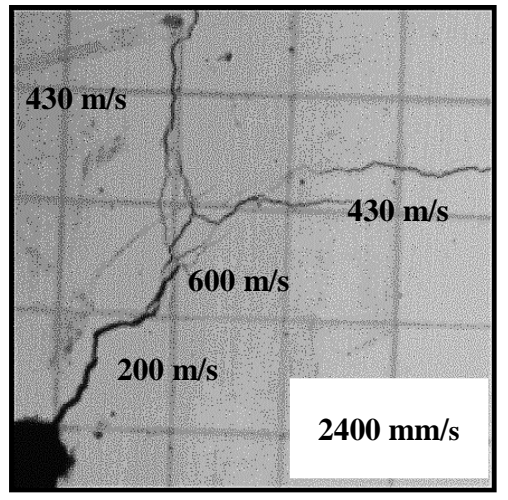

Figure 6: Experimentally measured crack velocities for loading rate $2.40 \mathrm{~m} / \mathrm{s}$.

The typical crack velocities evaluated from the experiments are marked in Fig. 6. The highest crack velocity is observed just before crack branching and is approximately equal to $650 \mathrm{~m} / \mathrm{s}$ (see Fig. 6). In most cases, after crack branching horizontal crack propagates slower than the vertical crack. It should be noted that the precision of the estimation of crack velocity is limited by the resolution of the camera.

\subsection{CT-Specimen}

The dimensions of the tested CT-specimen are: Length $\mathrm{x}$ Height $\mathrm{x}$ Thickness $=200 \times 200$ x $25 \mathrm{~mm}$; the notch length and width are 64 and $18 \mathrm{~mm}$, respectively. The specimen geometry and two steel frames, one loading and another reaction, are shown in Fig. 7. In contrary to the numerical study [9], the specimen is tested such that the notch is placed in horizontal position (see Fig. 7). Due to technical reasons the load is applied only at one (bottom) surface of the notch through displacement control of the bottom loading frame. The top steel frame is fixed at the top and served as reaction. Before the experiment the top and bottom steel frames are glued to the corresponding notch surfaces. The photo of the test set-up is shown in Fig. 8.

The concrete specimens are cured 7 days under constant temperature of $20^{\circ} \mathrm{C}$ and relative humidity $(\mathrm{RH})$ of $100 \%$. Subsequently the specimen is approximately three weeks exposed to RH of $60 \%$. The uni-axial compressive strength of concrete is measured before testing on standard cylinders, diameter and height of 150 and $300 \mathrm{~mm}$, respectively. The average strength (three specimens) was $f_{\mathrm{c}}=53 \mathrm{MPa}$. Mass density of concrete was assumed to be $\rho_{\mathrm{c}}=2400 \mathrm{~kg} / \mathrm{m}^{3}$ and maximum aggregate size was $8 \mathrm{~mm}$. The loading frames were made of normal steel with the following properties: Young's modulus $E_{\mathrm{s}}=210 \mathrm{GPa}$, Poisson's ratio $v=0.33$ and mass density $\rho_{\mathrm{s}}=7800 \mathrm{~kg} / \mathrm{m}^{3}$.

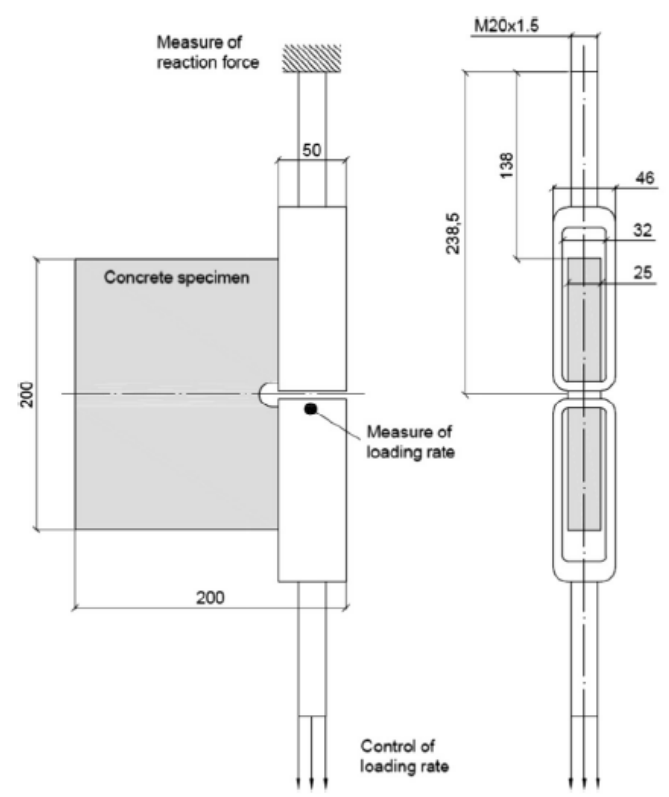

Figure 7: Geometry and test set-up of CT-specimen.

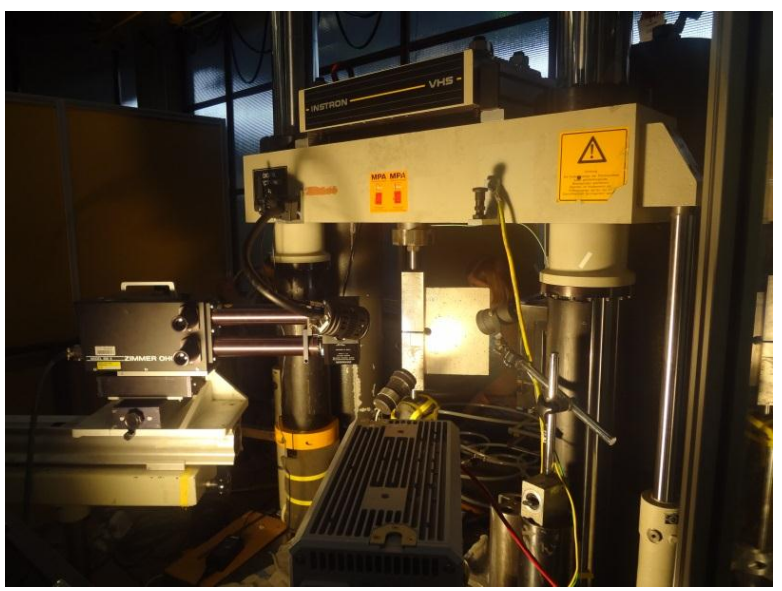

Figure 8: Test set-up.

In the experiments are measured displacement rates at the application of load (bottom loading frame) and at the contact of the loading frame and concrete. At the top steel frame is monitored the reaction. To estimate the crack velocity, in the zone of cracking, the experiment is recorded by high speed camera. 
Target (projected) loading rates at the point of load application (bottom of the loading frame) are varied from $0.10 \mathrm{~m} / \mathrm{s}$ up to $8.00 \mathrm{~m} / \mathrm{s}$. In total 12 experiments are carried out. (a)

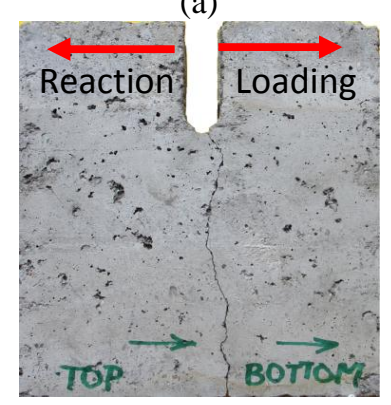

(c)

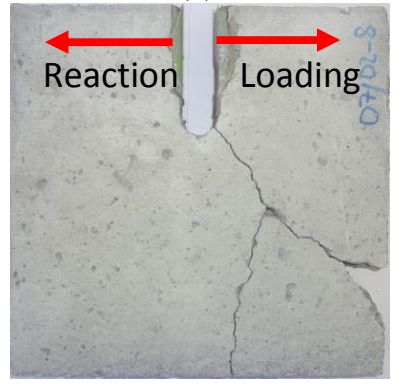

(b)

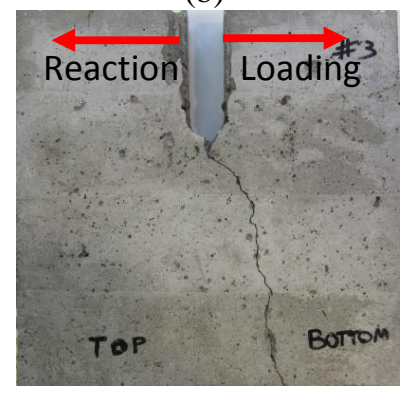

(d)

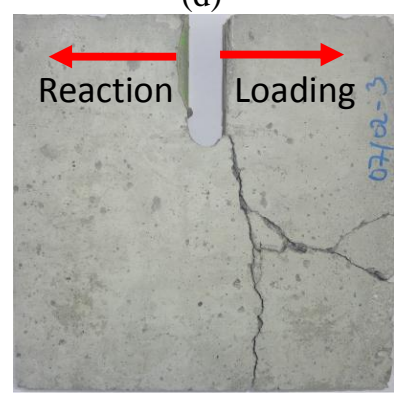

Figure 9: Experimentally observed crack patterns for displacement rates: (a) $0.304 \mathrm{~m} / \mathrm{s}$, (b) $1.375 \mathrm{~m} / \mathrm{s}$, (c) $3.318 \mathrm{~m} / \mathrm{s}$ and (d) $3.967 \mathrm{~m} / \mathrm{s}$.

Table 3: Summary of experimental results for CTspecimen

\begin{tabular}{cccc}
\hline Test Nr. $\begin{array}{c}\text { Displ. rate at } \\
\text { contact } \\
{[\mathrm{m} / \mathrm{s}]}\end{array}$ & $\begin{array}{c}\text { Max. } \\
\text { Reaction } \\
{[\mathrm{kN}]}\end{array}$ & $\begin{array}{c}\text { Number of } \\
\text { cracks }\end{array}$ \\
\hline 1 & 0.045 & 2.54 & $\mathrm{~S}$ \\
2 & 0.035 & 2.83 & $\mathrm{~S}$ \\
3 & 0.304 & 3.47 & $\mathrm{~S}$ \\
4 & 0.491 & 4.05 & $\mathrm{~S}$ \\
5 & 1.375 & 4.64 & $\mathrm{~S}$ \\
6 & 1.407 & 5.76 & $\mathrm{~S}$ \\
7 & 1.736 & 4.49 & $\mathrm{~S}$ \\
8 & 3.268 & 4.59 & $\mathrm{~B}$ \\
9 & 3.318 & 6.88 & $\mathrm{~B}$ \\
10 & 3.993 & 4.69 & $\mathrm{~B}$ \\
11 & 3.967 & 3.32 & $\mathrm{MB}$ \\
12 & 4.298 & 5.66 & $\mathrm{~B}$ \\
\hline
\end{tabular}

$\mathrm{S}=$ single $; \mathrm{B}=$ branching $\mathrm{MB}=$ multiple branching;

In Table 1 are summarized experimental results obtain from 12 performed tests. Shown are displacements rates applied at the contact between bottom loading frame and concrete, recorded maximum reaction and observed failure mode.

In Fig. 9 are shown typical crack patterns for displacement rates measured at the contact between concrete and bottom loading frame. It turns out that, for the tested geometry and concrete properties, there is only a single crack if the loading is less than approximately 2.0 to $3.0 \mathrm{~m} / \mathrm{s}$. For relative low loading rate, close to quasi static, the crack propagates almost perpendicular to the loading direction. However, for higher displacement rates the crack becomes inclined. The first crack branching is observed for displacement rate of approximately $3.30 \mathrm{~m} / \mathrm{s}$ and for higher displacement rates (approximately $4.0 \mathrm{~m} / \mathrm{s}$ ) even multiple crack branching is observed.

The measured reaction-displacement curves are shown in Fig. 10. The displacement is measured at the contact between concrete surface and loading frame. As expected, with increase of displacement (loading) rate the peak reaction increases.

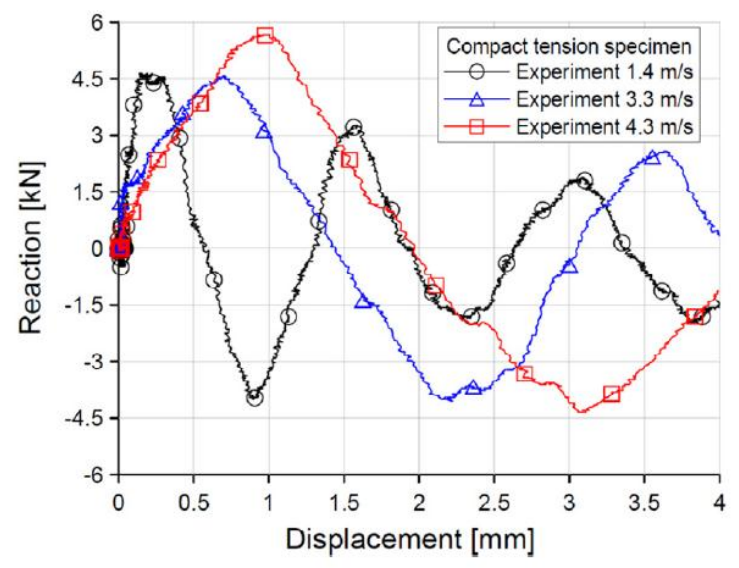

Figure 10: Experimentally measured reactiondisplacement response.

The same as for the L-specimen, the crack velocity is estimated from the evaluation of photos obtained from high resolution camera. The typical crack velocities evaluated from the experiments are shown in Fig. 11. The highest crack velocity of approximately $800 \mathrm{~m} / \mathrm{s}$ is detected in the Test Nr. 12 (see Table 3). 


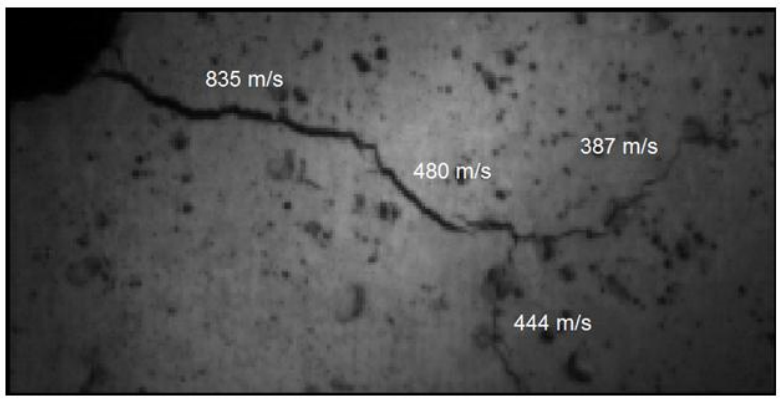

Figure 11: Experimentally measured crack velocities for loading rate $4.298 \mathrm{~m} / \mathrm{s}$.

\section{NUMERICAL POST-TEST ANALYSIS}

In order to better interpret the results of the experimental tests, especially with respect to the crack velocity, strain rate, rate dependent tensile strength and fracture energy, the above discussed tests are also simulated numerically. The numerical models exactly replicated the experimental setups. In the simulations the same 3D FE code as in the pre-test computations $[9,10]$ was used. The code is explicit and is based on the rate sensitive microplane model for concrete [7,14]. As a localization limiter crack band method is used [15].

\subsection{L-Specimen}

The spatial discretization of the L-specimen model is performed using constant strain four node solid finite elements (see Fig. 12). The material properties are set as the average values obtained from the measurements on concrete cubes (see Tab. 1) and are estimated based on the compressive strength. The overview of material properties used in the analysis is given in Tab. 4.

Figure 13 shows the comparison of the crack patterns obtained from the finite element analysis with those observed in the experiments. Note that the red zone represents strains that corresponds to the crack opening larger than critical strain $\varepsilon_{\mathrm{cr}}=w_{\mathrm{cr}} / h$, where $w_{\mathrm{cr}}$ is the assumed critical crack opening ( 0.10 $\mathrm{mm}$ ) and $h$ is the average element size (width of the crack band). As can be seen, there is a very good agreement between simulation and experiment. The numerical results show the same crack patterns as were observed in the experiments.

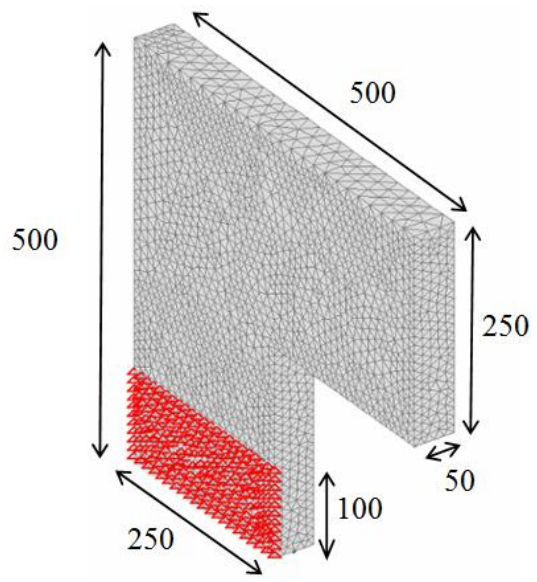

Figure 12: 3D finite element model of the L-specimen with boundary conditions (all in $\mathrm{mm}$ ).

Table 4: Summary of material properties used in the analysis

\begin{tabular}{lc}
\hline \multicolumn{2}{c}{ Concrete properties (L-specimen) } \\
\hline \hline Young's modulus, $E_{\mathrm{c}}(\mathrm{GPa})$ & 32.2 \\
Poisson's ratio, $v_{\mathrm{c}}$ & 0.18 \\
Mass density, $\rho_{\mathrm{c}}\left(\mathrm{kg} / \mathrm{m}^{3}\right)$ & 2210 \\
Tensile strength, $f_{\mathrm{t}}(\mathrm{MPa})$ & 3.12 \\
Compr. strength, $f_{\mathrm{c}}(\mathrm{MPa})$ & 46.25 \\
Fracture energy, $G_{\mathrm{F}}\left(\mathrm{J} / \mathrm{m}^{2}\right)$ & 58.56 \\
\hline
\end{tabular}

The numerically predicted and experimentally obtained crack patterns with the corresponding crack velocities are presented in Fig. 14. Both, the crack patterns and the crack propagation velocities from the numerical predictions display very good agreement with the experimental results. The results indicate that the crack propagation velocity depends on the loading rate. In general, it increases with the increasing displacement rate but once the crack reaches a critical speed of propagation, the crack branches and its further propagation velocity decrease. For the properties of concrete used here, experimentally obtained maximum crack speed is around $650 \mathrm{~m} / \mathrm{s}$, while in numerical analysis is equal to $750 \mathrm{~m} / \mathrm{s}$. 


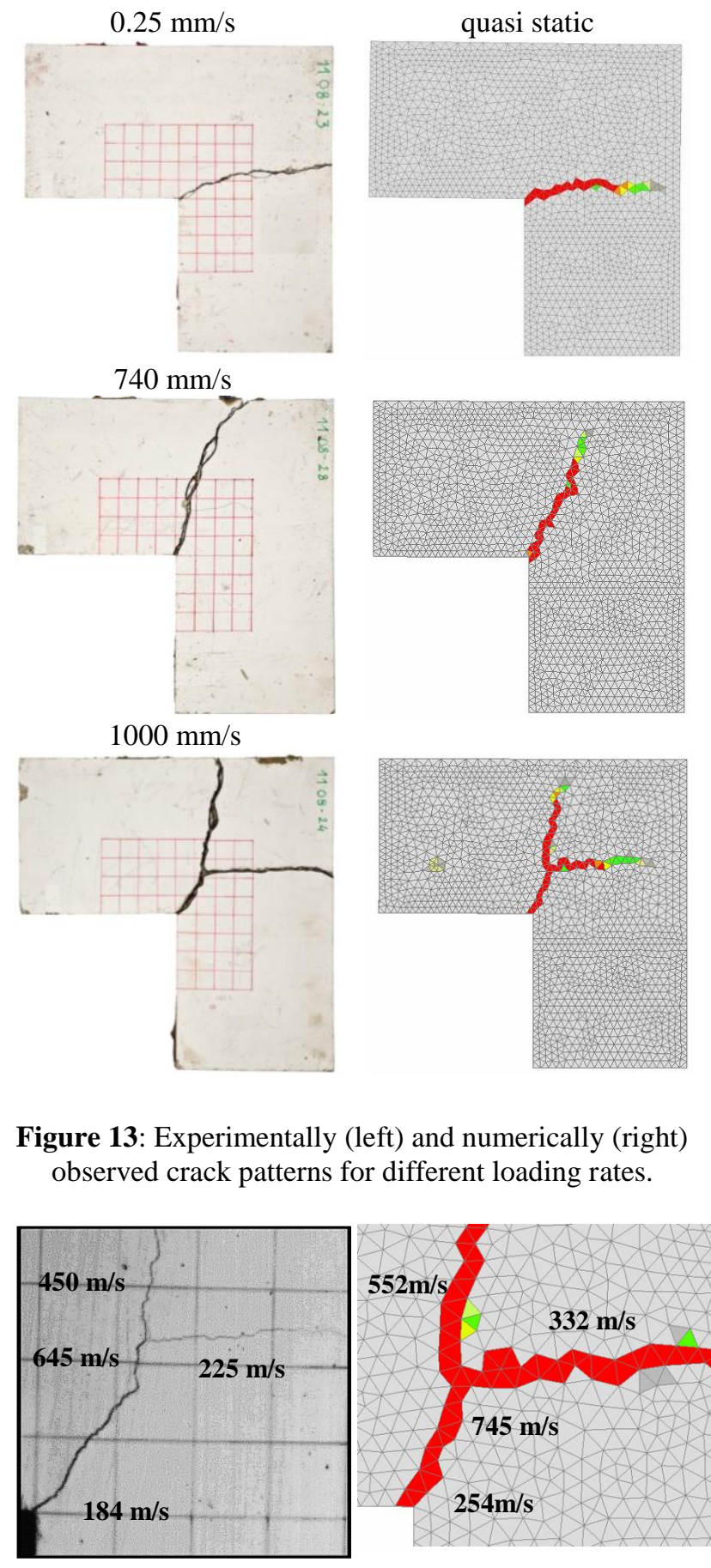

Figure 14: Experimentally (left) and numerically (right) observed crack velocities (loading rate $1.00 \mathrm{~m} / \mathrm{s}$ )

The results in terms of peak load as a function of displacement rate for seven representative tests and the corresponding numerical counterparts are summarized in Fig. 15. It can be seen that the numerical results follow the trend observed in the experiments. Up to a displacement rate of approximately $0.10 \mathrm{~m} / \mathrm{s}$ the peak load increases linearly, in semi-log scale, with increasing loading rate. However, for higher loading rates, the increase in the peak load becomes very strong and progressive. This phenomenon coincides with the change of the crack direction from nearly horizontal to nearly vertical without and with crack branching. Since the rate dependent constitutive law is approximately linear in semi-logarithmic scale, it is clear that the progressive increase of the peak load for higher loading rates shown in Fig. 15 is attributable to the inertia effects.

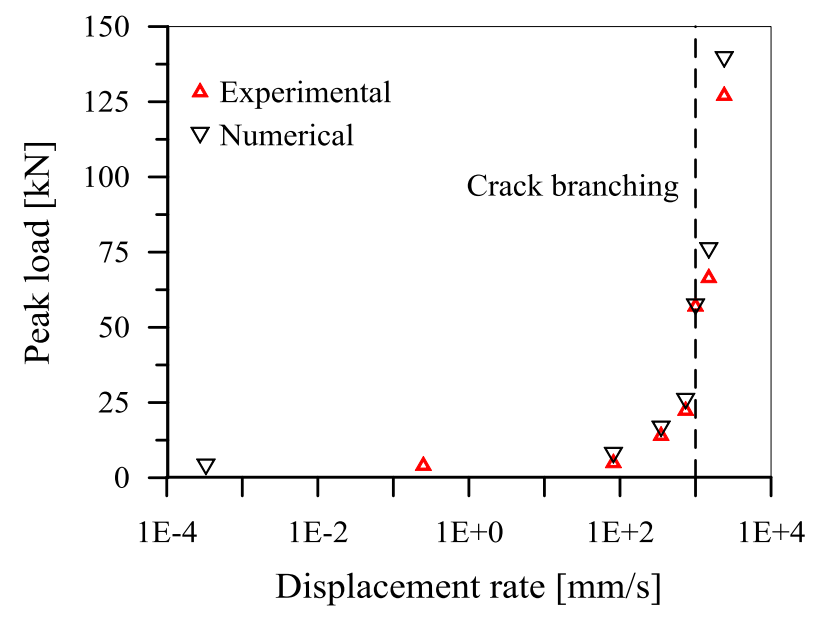

Figure 15: Comparison between numerical and experimental results for peak load at different loading rates.

Although experiments are necessary and helpful in understanding general behavior of concrete under high loading rates, there are limitations such as those related to the measurement of inherent material properties, e.g. rate dependent tensile strength and fracture energy. From the results of numerical analysis these properties can be easily obtained, however, it is important that the analysis is objective. The above comparison between numerical and experimental results confirmed that employed numerical model is able to realistically replicate the experimental tests. Therefore, the numerical prediction can be used to evaluate rate dependent material properties of concrete, which cannot be otherwise directly measured in the experiments. 

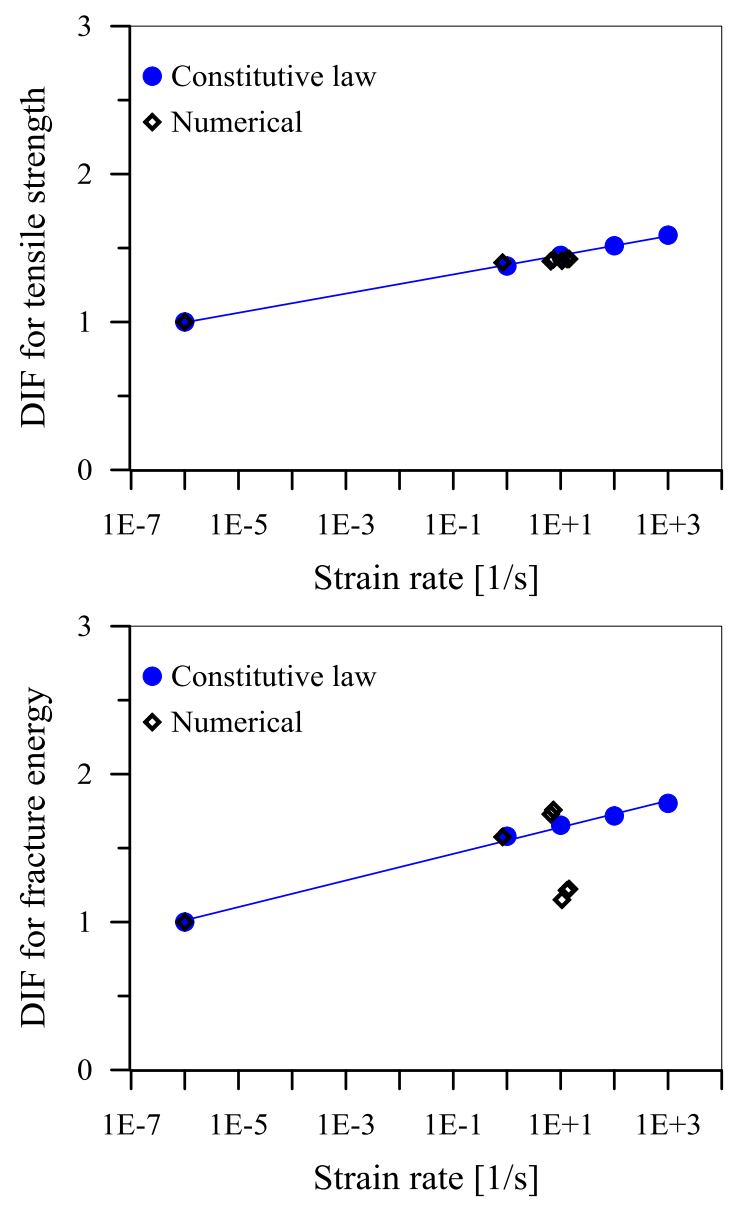

Figure 16: Numerically obtained DIF on tensile strength and fracture energy as a function of strain rate (L-specimen).

Dynamic increase factor (DIF) on true tensile strength and fracture energy evaluated from a single finite element, for the observed loading rates, are plotted in Fig. 16 as a function of strain rate. Note that the strain rate is measured at the onset of cracking. The true strength and fracture energy are not affected by inertia effects. As can be seen, there is no progressive increase of true strength and true fracture energy. Furthermore, it is clear that the strength nicely follow the rate dependent constitutive law. However, fracture energy seems to be less dependent on the strain rate, i.e. it is almost independent of the strain rate. This confirms that the strong and progressive increase in the peak load observed after the loading rate of $0.10 \mathrm{~m} / \mathrm{s}$ (see Fig. 15) is attributed to the inertia effects and it is not a consequence of progressive increase of intrinsic material strength and fracture energy.

\subsection{CT-specimen}

The same as for the L-specimen, to better interpret the results of the experimental tests, the numerical 3D finite element analysis is carried out using the same finite element code. The numerical model exactly replicated the experimental setup. Material properties, geometry, boundary conditions and loading are the same as in the experiment. In the FE discretization (see Fig. 17) four node solid finite elements are used. For steel loading and reaction frames linear elastic behavior is assumed. The contact between notch surface and steel plates is assumed to be perfect. The same as in the experiments, there is no contact between concrete side surfaces and loading frame. The displacement rates in the analysis are chosen such that corresponds to the experimental loading rates measured at the contact between loading plate and concrete.

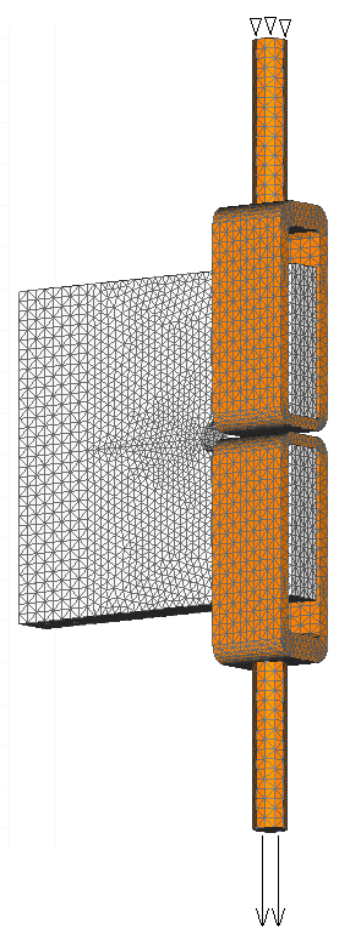

Figure 17: 3D finite element model of the CTS.

The concrete properties used in the analysis are estimated based on the average compressive strength $f_{\mathrm{c}}$. They are summarized in Tab. 5. 
Table 5: Summary of material properties used in the analysis

\begin{tabular}{lc}
\hline \multicolumn{2}{c}{ Concrete properties (CT-specimen) } \\
\hline \hline Young's modulus, $E_{\mathrm{c}}(\mathrm{GPa})$ & 36.0 \\
Poisson's ratio, $v_{\mathrm{c}}$ & 0.18 \\
Mass density, $\rho_{\mathrm{c}}\left(\mathrm{kg} / \mathrm{m}^{3}\right)$ & 2400 \\
Tensile strength, $f_{\mathrm{t}}(\mathrm{MPa})$ & 3.8 \\
Compr. strength, $f_{\mathrm{c}}(\mathrm{MPa})$ & 53.0 \\
Fracture energy, $G_{\mathrm{F}}\left(\mathrm{J} / \mathrm{m}^{2}\right)$ & 65.0 \\
\hline
\end{tabular}
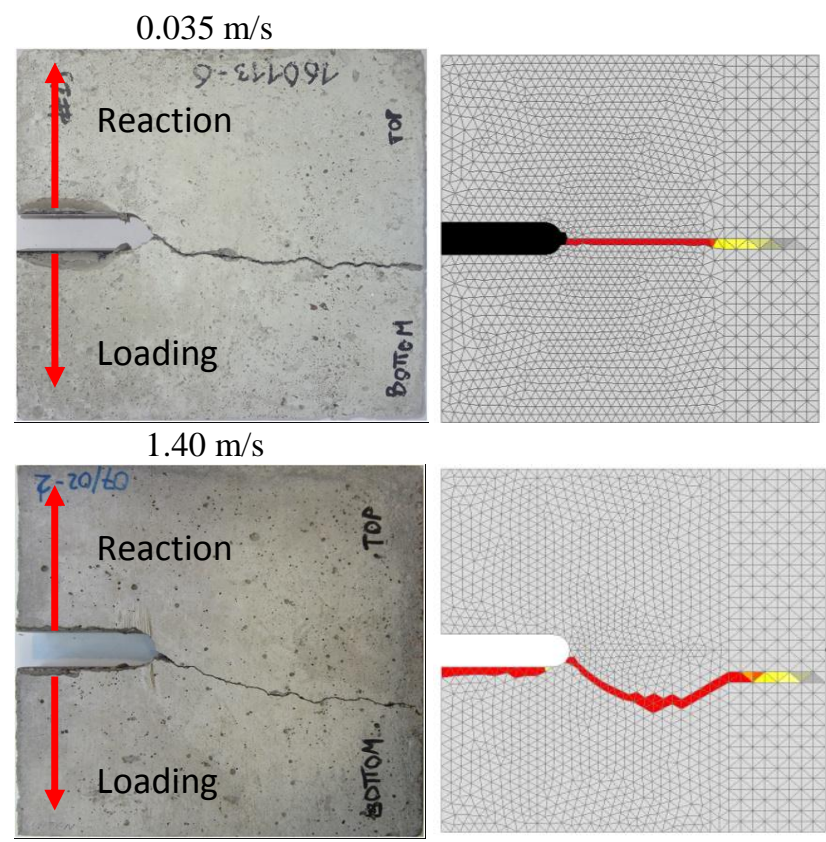

$4.3 \mathrm{~m} / \mathrm{s}$
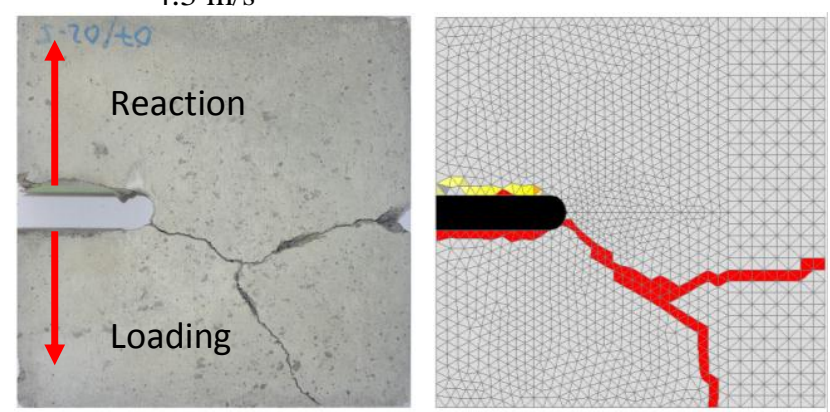

Figure 18: Experimentally observed (left) and numerically predicted crack patterns in terms of max. principal strains (right).

In Fig. 18 are compared crack patterns for loading rates in the range between 0.035 and $4.30 \mathrm{~m} / \mathrm{s}$. For quasi-static and relative low loading rates the crack is nearly horizontal (perpendicular to the loading direction), however, with increase of loading rate the crack becomes more inclined. The first crack branching in both cases is obtained for loading rate of $3.30 \mathrm{~m} / \mathrm{s}$.
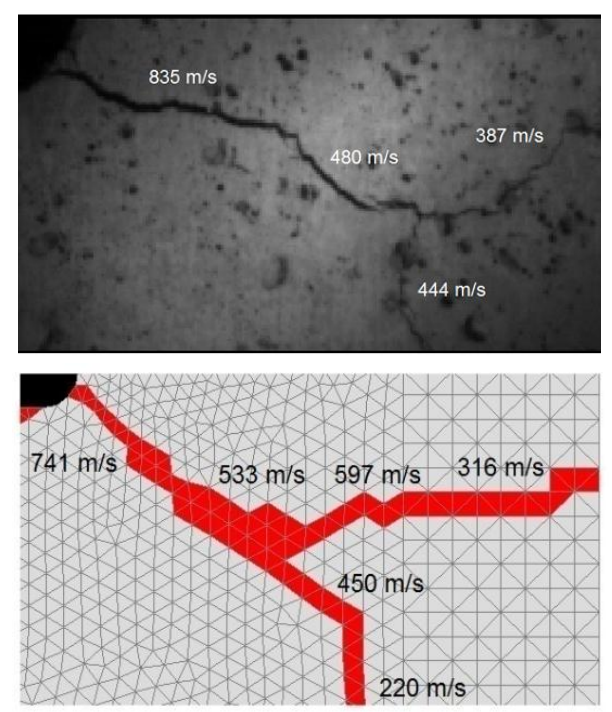

Figure 19: Measured and numerically predicted crack velocities for loading rate $4.30 \mathrm{~m} / \mathrm{s}$.
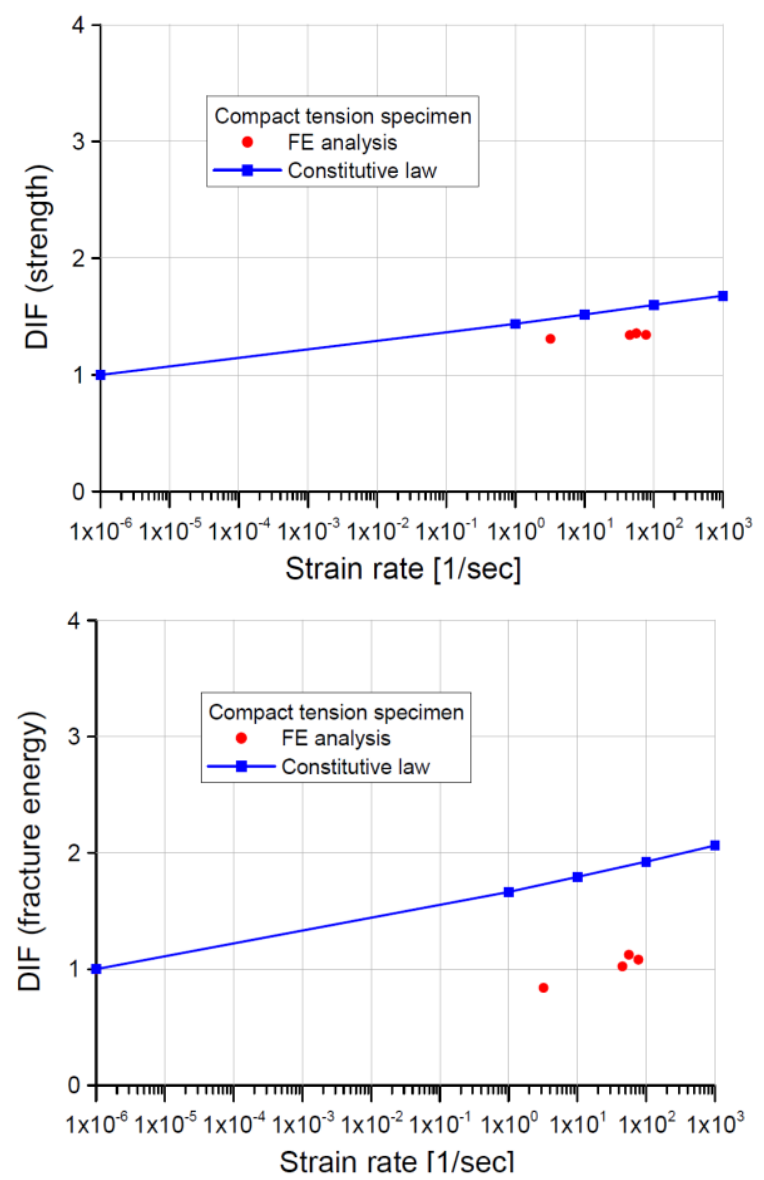

Figure 20: Numerically obtained DIF for tensile strength and fracture energy of concrete as a function of strain rate (CT-specimen).

In Fig. 19 are shown predicted and 
experimentally obtained crack patterns with corresponding crack velocities (loading rate $4.30 \mathrm{~m} / \mathrm{s}$ ). For used properties of concrete maximum crack speed is around $800 \mathrm{~m} / \mathrm{s}$. As discuss in detail by Ožbolt et al. [11], after crack velocity reaches critical speed (around $800 \mathrm{~m} / \mathrm{s}$ ), there is crack branching.

Figure 20 shows DIF for measured tensile strength and fracture energy as a function of strain rate. The strength follows approximately the rate dependent constitutive law. In contrast, similar to the L-specimen, it is interesting to observe that DIF on fracture energy does not follow the rate dependent fracture energy from the constitutive law, i.e. it is almost independent of the strain rate. The reason for this could be the fact that, due to inertia effects at the crack tip, the part of the energy is consumed by damage that takes place before the crack is localized.

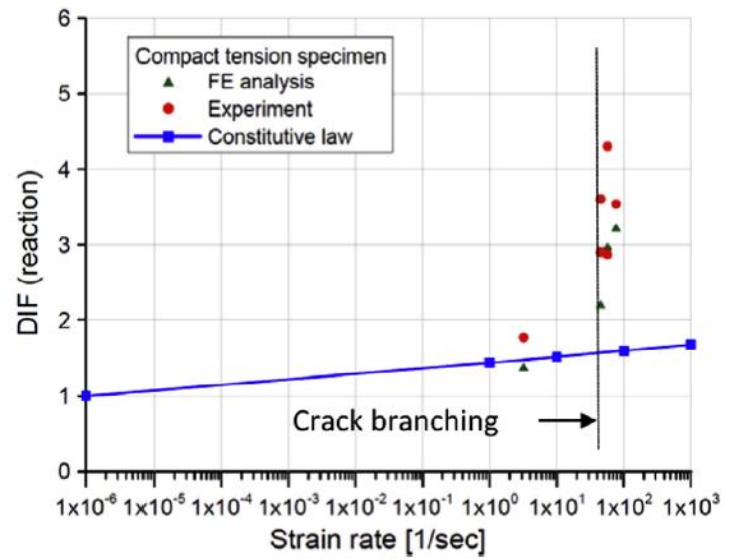

Figure 21: DIF for reaction, predicted experimentally and numerically, and compared with DIF for tensile strength of concrete.

Figure 21 shows DIF on reaction force measured in the analysis and experiment as a function of strain rate. Up to the strain rate of approximately $50 / \mathrm{s}$ there is linear increase in DIF on resistance (reaction), which nicely follows the rate dependent constitutive law for tensile strength. Obviously, in this strain rate range, reaction is controlled by the rate dependent constitutive law. However, for higher strain rates $(d \varepsilon / d t>50 / \mathrm{s})$ there is progressive increase of reaction. Since the experimental and numerical results agree well, it can be concluded that the reason for the progressive increase cannot be the tensile strength and fracture energy, which show no progressive increase (see Fig. 20). The same as for the L-specimen, this progressive increase is controlled by inertia effects. It is interesting to observe that the progressive increase of resistance coincides with the crack branching, which is experimentally and numerically observed for $d \varepsilon / d t>50 / \mathrm{s}$. Consequently, it can be concluded that both phenomena are controlled by inertia.

\section{CONCLUSIONS}

In the present contribution the influence of the loading rate on the concrete L- and CTspecimens is experimentally and numerically studied. The tests are carried out in order to verify the results of numerical prediction performed recently $[9,10]$. Based on the evaluation of experimental and numerical results the following can be concluded. (1) The evaluation of the test results confirms the results of numerical prediction. It is shown that relatively simple modeling approach based on continuum mechanics, rate dependent microplane model and standard finite elements is capable to realistically predict complex phenomena related to dynamic fracture of concrete. (2) Experiments and analysis show that the loading rate significantly influences the resistance and failure mode of concrete specimens. For strain rates, lower than approximately 50/s, the resistance is controlled by rate dependent constitutive law. However, for strain rates larger than 50/s, the influence of inertia dominates. (3) The progressive increase of resistance (reaction forces) for $d \varepsilon / d t>50 / \mathrm{s}$ is a consequence of inertia and is not related to the rate dependent strength of concrete, which is approximately linear in semi-log scale and is controlled by the constitutive law. (4) The evaluation of the numerical results shows that fracture energy does not follow fracture energy dependency from the constitutive law, which is linear in semi-log scale. Instead, it is approximately independent from the strain rate. The reason is attributed to the 3D effect at the notch tip and related inertia forces that caused 3D tensile 
stress state. (5) For strain rates $d \varepsilon / d t<50 / \mathrm{s}$ the failure mode is due to mode-I fracture, however, for $d \varepsilon / d t>50 / \mathrm{s}$ mixed failure mode is observed. (6) The evaluation of test and numerical results show that for $d \varepsilon / d t>50 / \mathrm{s}$ there is crack branching. The phenomenon is related with progressive increase of resistance (reaction) and is controlled by inertia effects. (7) The experiments and analysis confirm that crack velocity depends on the current crack pattern. For the here investigated normal strength concrete the highest measured crack velocity reaches approximately $800 \mathrm{~m} / \mathrm{s}$ and is measured at the onset of crack branching. After crack branches the crack velocity drops down. (8) The investigated relatively simple L- and CT-specimens can be employed for the verification and calibration of numerical models for concrete under dynamic loading.

\section{REFERENCES}

[1] Freund, L.B. 1972. Crack Propagation in an Elastic Solid Subjected to General Loading-I. Constant Rate of Extension. $J$ Mech Phys Solids 20: 129-40.

[2] Dilger, W.H. Koch, R. and Kowalczyk, R. 1978. Ductility of plain and confined concrete under different strain rates. $A C I$ Special publication, Detroit.

[3] Reinhardt, H.W. 1982. Concrete under impact loading, tensile strength and bond. Heron 27 (3).

[4] Curbach, M. and Eibl, J. 1990. Crack velocity in concrete. Engng Fract Mech 35 (1-3): 321-26.

[5] Bischoff, P. and Perry, S. 1991. Compressive behaviour of concrete at high strain rates. Mat and Struct 24: 42550.

[6] Rabczuk, T. and Belytschko, T. 2004. Cracking particles: a simplified meshfree method for arbitrary evolving cracks. Int $J$ Num Meth Engng 61: 2316-43.

[7] Ožbolt, J., Rah, K.K. and Mestrović, D. 2006. Influence of loading rate on concrete cone failure. Int $J$ Fract 139: 239-52.

[8] Weerheijm, J. and Van Doormaal, JCAM. 2007. Tensile failure of concrete at high loading rates: new test data on strength and fracture energy from instrumented spalling tests. Int J Impact Eng 34 (3): 609-26.

[9] Ožbolt, J., Sharma, A. and Reinhardt, H.W. 2011. Dynamic fracture of concrete - compact tension specimen. Int J Solids and Structs 48: 1534-43.

[10] Ožbolt, J. and Sharma, A. 2012. Numerical simulation of dynamic fracture of concrete through uniaxial tension and L-specimen. Eng Fract Mech 85: 88-102.

[11] Ožbolt, J., Bošnjak, J. and Sola, E. 2013. Dynamic fracture of concrete compact tension specimen: Experimental and numerical study. Int J Solids Struct 50: 4270-78.

[12] Ožbolt, J., Bede, N., Sharma, A. and Mayer, U. 2015. Dynamic fracture of concrete L-Specimen: Experimental and numerical study. Eng Frac Mech 14: $27-$ 41.

[13] Irhan, B., Ožbolt, J. and Ruta, D. 2015. 3D Finite Element Simulations of High Velocity Projectile Impact. Int J Solids Struct 72: 38-49.

[14] Ožbolt, J., Li, Y.J. and Kožar, I. 2001. Microplane model for concrete with relaxed kinematic constraint. Int J Solids and Struct 38 (16): 2683-711.

[15] Bažant, Z.P. and Oh, B.H. 1983. Crack band theory for fracture of concrete. Mater Struct RILEM 16 (3): 155-77. 